\title{
The Development of Rural Microinsurance in Sichuan Province - an Analysis from the Perspective of Risk Management
}

\author{
Huidan Xu \\ School of Economics, Sichuan Agricultural University, Chengdu, Sichuan, 611130, China
}

Keywords: Rural, Micronsurance, Risk factors, Risk management

\begin{abstract}
As a new type of insurance program, microinsurance has begun to appear in rural areas of some developing countries and is developing rapidly. Microfinance is an inevitable product of the spread of modern financial services to rural areas, and has gradually become a means of poverty alleviation and development, which has been widely adopted by more and more developing countries. Based on the author's learning and practical experience, this paper first analyzed the risk factors in rural micro-insurance in Sichuan Province, and then put forward the corresponding prevention and control strategy. The results of this study will help to build a new rural risk management system with small insurance as the core, promote the development of rural economy and accelerate the construction of new rural areas in China.
\end{abstract}

\section{Introduction}

Affected by the promotion of microinsurance in many developing countries, China has also begun to promote rural microinsurance. Microinsurance is a kind of insurance protection for low-income groups, which is operated according to accepted insurance principle. Its products include small life insurance, small health insurance, small accident insurance and small agricultural and property insurance. It has low premiums, low coverage, and specific risks to low-income people, such as illness, death, disability, etc. Its insurance terms are easy to understand and easy to verify with simple business process and other characteristics. At present, the rural microinsurance in China includes small life insurance, new medical insurance, land-requisition farmer pension insurance, migrant workers accident injury insurance and so on, and has achieved certain results. However, due to the rural microinsurance in China has just started, there are still some problems in the development of rural microinsurance, such as coverage is not enough, supply efficiency is not high, service quality cannot keep up with lacking of effective policy support and legal norms. Therefore, it is necessary to analyze the risk factors in the development of microinsurance and carry out effective management.

\section{Risk Factors in Rural Microinsurance in Sichuan Province}

The overall goal of the construction of new countryside is "production development, rich life, civilized style of countryside, clean and tidy village, democratic management". In the final analysis, it is to solve the problem of economic development in rural areas. The study of development economics shows that the diversity of rural risks and the vulnerability of rural families are the main factors restricting the development of rural economy. Vulnerability is the expected loss of welfare when a family or individual is at risk. The vulnerability of families to risk events is the extent to which families tend to become poor. Vulnerability depends on the frequency of risk events, their scale and the ability of households to manage them effectively. Compared with the city, the risks faced by rural families in China have three significant characteristics: First, it is complexity. The rural population density is low with scattered residence; moreover, the medical and health infrastructure is not perfect, with complicated social custom, and is affected by many kinds of risk factors. Second, it is centralization. The industrial structure of rural economy is single. In general, agriculture occupies an absolute dominant position with its production process is seasonal and strong dependence on climate conditions; moreover, product price is in volatility, and rural 
households cannot fully achieve income diversification. Consumption depends on agricultural income to a large extent, and exposure to agricultural risks is relatively concentrated. Third, it is universality. Farmers generally have poor nutritional status, low levels of education, low cash income and poor stability. Dealing with crop failure, disease, death and other recurring risk events, coping with shocks, smooth consumption is the main content of rural household production and life. These characteristics of rural economy determine that rural families have a very urgent need for risk management.

In theory, the risk management mechanisms that rural families can use include two types of formal and informal mechanisms. Formal mechanisms include financial services provided by financial markets, security schemes implemented by the public sector and agricultural support policies; Informal mechanisms include raising animals for preventive savings, obtaining loans from social networks formed between relatives and friends, and usurping loans. On the whole, the formal mechanism is faced with enormous institutional rigidity in its operation, and the coverage and the degree of security are far from meeting the needs of rural families. Rural families often rely on informal risk management mechanisms to resist risks. In other words, the rural formal risk management mechanism is absent in reality, while the informal insurance system is difficult to fully spread the risk in space and time, and it is inevitable that the efficiency is low, which leads to the high vulnerability of rural families. First of all, the failure to effectively manage risks reduces the efficiency of agricultural production. As a result of the lack of effective means of increasing revenue and smoothing consumption, rural households generally adopt low-efficiency production techniques to guarantee the stability of income and consumption. The cost of this strategy is high. According to the World Bank statistics, giving up more than 20 percent of the expected income can obtain a relatively stable income stream. Secondly, the effectiveness of risk management directly determines the fairness of rural economic development. For example, some rural economies have developed in general, but some of them are poorer because of their inability to withstand risk losses. Third, weak risk management leads to lower levels of nutrition and education. After the occurrence of the risk events, farmers will be forced to reduce the standard of life or reduce the educational investment of family members, causing a vicious cycle of poverty. Therefore, the lack of formal risk management mechanism has become a major bottleneck restricting rural economic development and new rural construction.

\section{Countermeasures of Risk Prevention and Control in Rural Microinsurance}

\subsection{Perfecting Inclusive Financial Supervision System}

It is the basic requirement of financial development to establish a standard and loose regulatory environment. We should strengthen the concept of supervision and carry out effective supervision. Both the fight against risk and innovation will play a role in strengthening. Strengthening the inclusive financial management system, separating the corporate management of inclusive finance from government supervision. Also, we should set up inclusive financial industry association and strengthen the management of inclusive financial institutions. We should control the entry threshold of inclusive financial institutions, do our best to carry out risk management, and use national legal means to regulate the fairness and rationalization of inclusive financial system. We also need to innovate in the management of financial institutions and improve efficiency and control of risk through management innovation. Moreover, we should introduce new technologies and new means to optimize the management of credit processes.

\subsection{Development of New Inclusive Financial Institutions}

The penetration and coverage of China's current financial system from the inclusive financial system in the financial market cannot meet the needs of inclusive finance. Therefore, on the basis of strengthening the regulation of financial institutions and relaxing access policies, new facilities should be allowed to enter the financial market. We should standardize the development of various forms of new financial institutions, especially the various types of capital entering financial 
institutions to focus on the lack of network coverage, inadequate financial competition and the establishment of local investment institutions. In order to ensure the normal and healthy development of microfinance companies, rural banks and other new financial institutions should seriously sum up experience and lessons, improve the relevant loan system; moreover, we should strengthen regulatory measures and oversight mechanisms to ensure the independence and effectiveness of regulation. New financial institutions should continue to improve internal control mechanisms and strengthen risk control levels to provide low-cost, convenient and affordable financial services for commercial sustainability.

\subsection{Reasonable Formulate Interest Rate Coverage Risk Management Cost}

Reasonable interest rates have two meanings: First of all, we should be able to meet the needs of vulnerable groups for funds; secondly, it can cover the management cost, capital cost and loan loss of microfinance institutions. It can be seen that reasonable interest rate is of great significance to the full realization of micro-credit. If the cost of risk management cannot be covered by interest, the improvement of risk management ability will become meaningless.

\subsection{Implement a Scientific Internal Management System}

To sum up, creating a good financial environment is a very important aspect of internal risk management. It is of great significance for the development of microfinance institutions to strengthen the management of institutions and improve the ability of risk management. Microfinance institutions should strengthen the management of loan process, and how to realize the unification of loan process efficiency and cost in a larger scope is the problem that microfinance institutions must solve. Therefore, with the support of relevant government agencies, the computer and mobile communication technology can be applied to the business process as much as possible, so that the loan operation process can be standardized.

\section{Summarization and Prospect}

How to rapidly improve the development level of rural financial markets and expand the coverage of rural financial services is a problem that must be solved in the development of rural economy, and it is also a huge challenge facing the governments of various countries. The practice and development of microinsurance provide a new way to solve this problem. Because microinsurance is an industry of managing risk and is full of all kinds of risks in the whole credit process, it is necessary to study the problem of credit risk in depth. However, credit risk is a very complex system, and there are many influencing factors. This paper only analyzes and evaluates some important soil factors, but does not take some secondary index factors into account. For example, microcredit interest rate risk, exchange rate risk and monetary policy risk. Although these risks are also very important to microcredit institutions, China's macro-financial policies have strict control mechanisms on interest rates and exchange rates. Interest rate and exchange rate fluctuations have little or no effect on microcredit compared with other financial institutions.

The countermeasures and suggestions of microcredit risk management need to be tested in practice. Because of the special situation of our country, the risk management of microcredit is not perfect. Compared with other developing countries, there is still a certain distance between theoretical research and empirical analysis. The proposal of prevention and control of microcredit risk was only some frame countermeasures, and had not been discussed in depth and concretely. Therefore, the validity of these recommendations needs to be tested in future practice.

\section{Acknowledgements}

Project Foundation: Project of Sichuan Rural Development Research Center (CR1308). 


\section{References}

[1] Gao Peng, Xu Yunsi, Dong Yingming, Wu Xian. Research on the Development of Personal Insurance in Rural Areas of Hebei Province [J]. Co-operative Economy and Science and Technology 12: 49-50.

[2] Xing Tingting, Zhang Xing. A New Institutional Economics Perspective on the Development of Rural Microinsurance [J]. Economic problems 2013, (06):99-103.

[3] Zhang Lu. Some Thoughts on Perfecting the Rural Small Insurance in China [J]. South Finance: 01a: 77-79.

[4] He Min. Development and Thinking of Microcredit Insurance in Jiangsu Province [J]. Financial vertical and horizontal Journal, 2012, (12):53-57+62.

[5] Chen Taiming, Sun Qiang, Sun Yiwen. Some Reflections on Microcredit Insurance from Country to Town: from the Perspective of Risk Management [J]. 2010, (01):105-106.

[6] Yuan Wei, Yang Mingliang. To Build a New Rural Risk Management System based on Microinsurance as the Core [J]. Economic Management, 2009, (05): 167-169.

[7] Zhu Junsheng, Tuo Guozhu. The Key to Promote the Development of Small Insurance is to improve the Efficiency of Supply [J]. Chinese Finance, 2009, (05): 44-46. 